\title{
A TVWS Quantification Aproach for Mexico.
}

\author{
Cuevas-Ruíz, J.L.
}

Abstract - In this paper a TVWS available spectrum is calculated, applying some procedures defined for regulatory authorities. The coverage was estimated using the Longley Rice method and the FCC recommendation was applied to delimit geographical zones, defining the occupied and free frequencies.

Keywords - TVWS, Longley-Rice.

\section{INTRODUCCTION}

Around the world, there is a growing demand for radio spectrum. One alternative to get more spectrum is the Secondary access to the unused spaces in TDT (Terrestrial Digital Television), named as TVWS (Television White Spaces). This alternative represent a promising application and a way to increase the spectrum efficiency. The secondary access implementation could be based on cognitive radio strategies, principally the so-called geolocalized databases; these databases will contain all the information regarding to the licenses frequencies (occupied channels) in the geographical area where the secondary users are situated, therefore they are able to identify the unused spectrum segments, defined as TVWS. When a secondary user wants to transmit, the database assign to the potential secondary user a free TVWS, indicating several technical conditions and monitoring the link performance (duration, interference levels, etc.).

There are several uses and applications cited in the bibliography using the TVWS, by means of the implementation of low power low range wireless networks; some operational and technical characteristics for these networks are defined in the 802.22 IEEE standard.

In this paper is applied a methodology to quantify the radio spectrum available by means of the TVWS.

\section{METHODOLOGY}

Using the technical data for all the TDT transmitter along the country, the coverage area for each channel was estimated; this evaluation was done applied the LongleyRice propagation model [9], which is able to estimate the attenuation levels for $20 \mathrm{MHz}$ to $40 \mathrm{GHz}$ frequencies transmissions. In Fig. No. 1 is showed the results obtained for the 41 channel in the Aguascalientes city. Once that the all the coverage area were obtained, a 84 cities distributed along the country was defined as a sample to identify the possible TVWS available in these cities

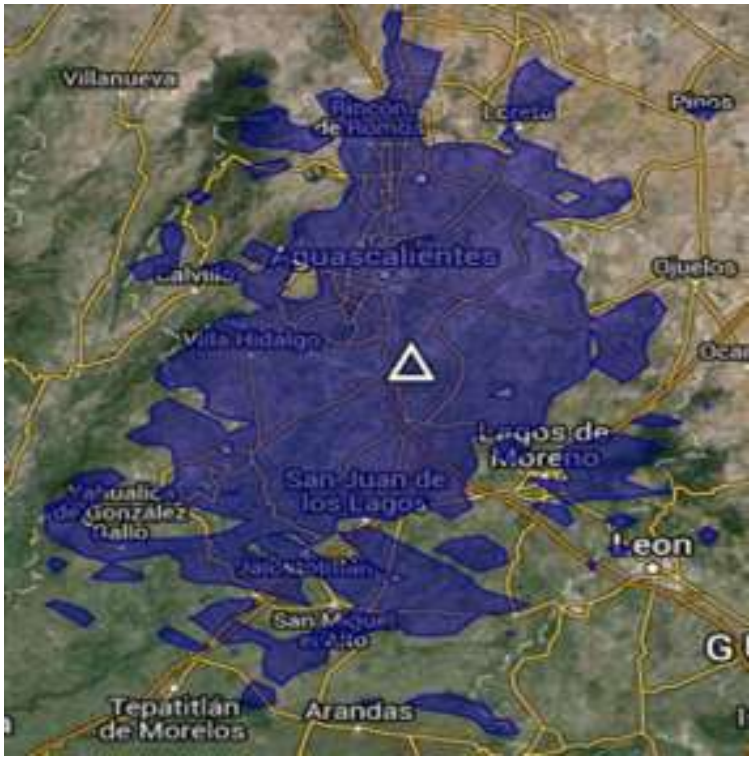

Figure No. 1. Coverage are for the Aguscalientes City..

The procedure to evaluate the potential TVWS is described next.

- The TDT cannel coverage areas were obtained using the Longley-Rice method. In the Table No. is showed the TV transmitters by state.

\begin{tabular}{|l|c|l|c|}
\hline \multicolumn{1}{|c|}{ Estado } & No. Canales & \multicolumn{1}{c|}{ Estado } & No. Canales \\
\hline Ags & 7 & Mor & 5 \\
\hline BC & 16 & NL & 21 \\
\hline BCS & 12 & Nay & 11 \\
\hline Campeche & 11 & Oax & 29 \\
\hline Chihua & 26 & Puebla & 7 \\
\hline Chiapas & 30 & Q. Roo & 9 \\
\hline Coah & 24 & Qro & 7 \\
\hline Colima & 12 & SLP & 15 \\
\hline Cd de Méx & 14 & Sin & 14 \\
\hline Dgo & 15 & Son & 39 \\
\hline Gro & 17 & Tab & 12 \\
\hline Gto & 26 & Tamps & 24 \\
\hline Hgo & 13 & Tlaxc & 5 \\
\hline Jal & 18 & Ver & 21 \\
\hline Edo Mex & 11 & Yuc & 9 \\
\hline Mich & 27 & Zac & 16 \\
\hline \multicolumn{2}{|c|}{ Table No. 1. TDT channels per state }
\end{tabular}

For each one of the transmitters, the attenuation profile is calculated, according to next expression, defined in the Longley Rice procedure: 
Proc. of the Fourth International Conference on Advances in Computing, Electronics and Communication - ACEC 2016. Copyright (C) Institute of Research Engineers and Doctors. All rights reserved.

ISBN: 978-1-63248-113-9 doi: 10.15224/ 978-1-63248-113-9-60

$$
W(t, \ell, s)=w_{0}+y_{s}(s)+\delta_{L}(s) y_{L}(\ell)+\delta_{L}(s) y_{T}(t)
$$

Where $\mathrm{W}$ represent the total attenuation level, $\mathrm{w}_{0}$ is the free space attenuation and the random variables $y_{s}(s)$, $y_{L}(\ell)$ y $y_{T}(t)$ represent the attenuations due to the site topographic conditions, atmospherics issues and the tx/rx localization [9]. The $\delta$ variable represent the level attenuation deviation. In this way, the maximun coverage distance, $d_{\text {maxi }}(W)$, is defined as the distance between the cannel transmitter tower, $P_{\text {chi }}\left(\right.$ lat $_{\text {chi }}$, long $\left._{\text {chi }}\right)$, and the point where the signal be received at 48 $\mathrm{dBu}$ power.

- To declare if a some city is located inside the coverage area for any of the cannel, the distance between the ith channel tower transmission, $P_{c h i}\left(l_{\text {at }}\right.$ chi, $\left.\operatorname{long}_{\text {chi }}\right)$, and the city geographical coordinates $P_{c}\left(\right.$ lat $_{c}$, long $\left.g_{c}\right)$. To get these distance, teh Haversine function was used. This function is defined as

$$
\begin{aligned}
\text { haversin }\left(\frac{d_{i c}}{R}\right)= & \text { haversin }\left(\text { lat }_{c h i}-\text { lat }_{c}\right) \\
& +\cos \left(\text { lat }_{c h i}\right) \cos \left(\text { lat }_{c}\right) \text { haversin }(\Delta \lambda)
\end{aligned}
$$

where

$$
\begin{aligned}
& \text { haver } \sin (\theta)=\left(\sin \left(\frac{\theta}{2}\right)\right)^{2} \\
& d_{i c}=i \text { transmitter and c city distance. } \\
& R=\text { Earth radium. } \\
& \Delta \lambda=\text { longitude diference. }
\end{aligned}
$$

\section{RESULTS}

For all the cities in the simple, was identified the principal and adjacent channels. Using this information, the TVWS was obtained for each city; a sample of this results is showed in Fig. No.2

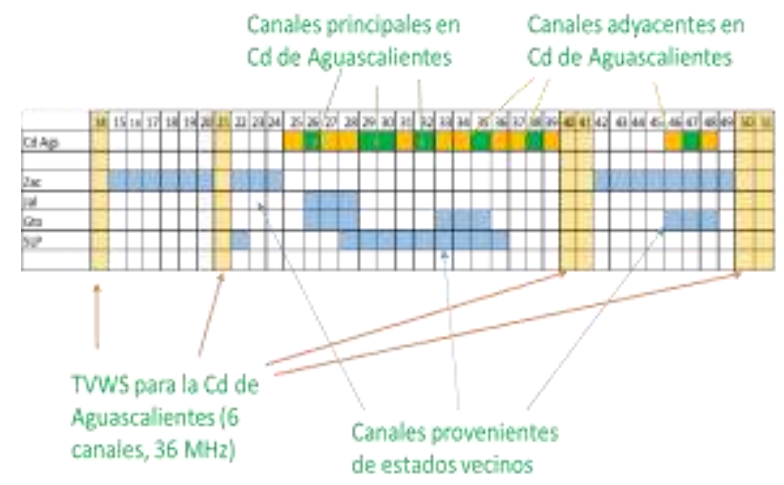

Figure No. 2. TVWS identification procedure.

Using the data obtained, a estimation for the TVWS number available for state was done. Fig. No. 3. A TVWS distribution map was elaborated using this information. Fig. No. 4

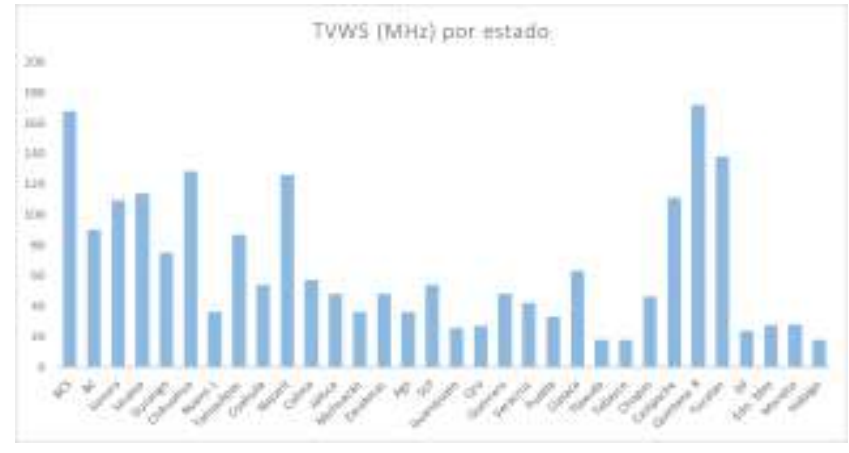

Figure No. 3. Available spectrum by state.

\begin{tabular}{|c|c|c|}
\hline kecion & TVWS [Mith] & 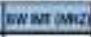 \\
\hline 1 & 109.25 & 30235 \\
\hline 2 & 10600 & 312.45 \\
\hline 1 & $96 \%$ & 3168 \\
\hline 4 & 7550 & 313,8 \\
\hline 5. & 400 & 313.45 \\
\hline 6 & 4120 & $318 \%$ \\
\hline 2 & 393 & $313 x$ \\
\hline 8 & 19000 & 31545 \\
\hline 9 & 2509 & 3018 \\
\hline Averay & 7159 & $31<x$ \\
\hline
\end{tabular}

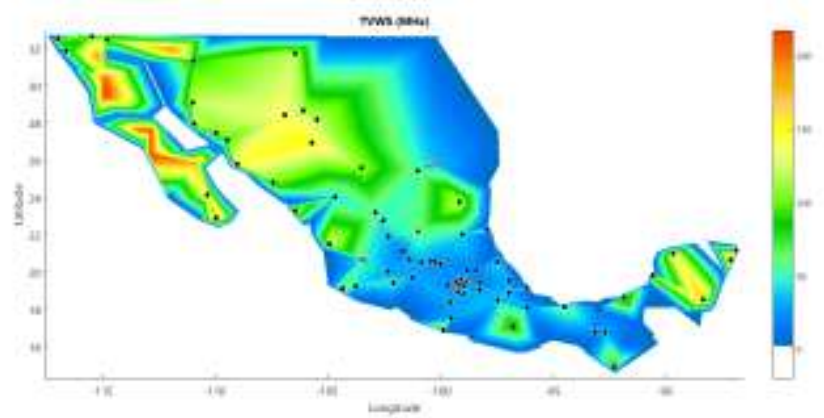

Figure No. 4. TVWS distribution.

Comparing the total radio spectrum available by the TVWS alternative, we compare it with the total spectrum dedicated in Mexico for IMT services. The data was exposed in Table No. 2 Fig. No. 5.

Table No. 2. Spectrum for IMT and TVWS for cellular zone.

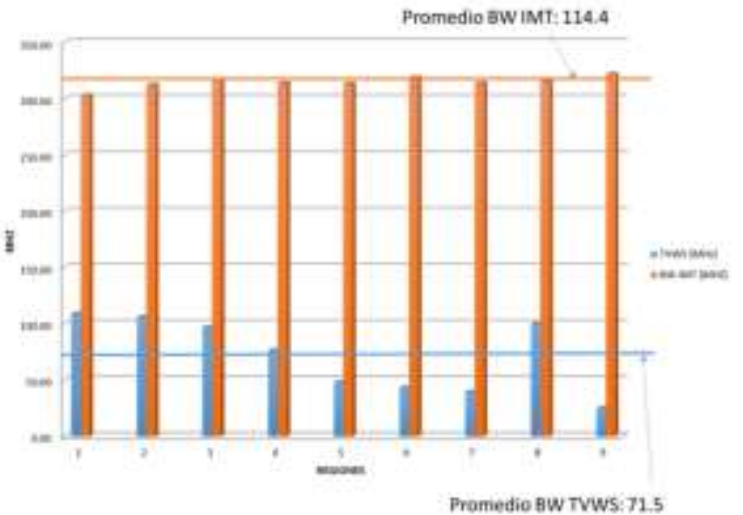


Proc. of the Fourth International Conference on Advances in Computing, Electronics and Communication - ACEC 2016.

Copyright (C) Institute of Research Engineers and Doctors. All rights reserved.

ISBN: 978-1-63248-113-9 doi: 10.15224/ 978-1-63248-113-9-60

Figure No. 5. Spectrum for IMT and TVWS for cellular zone.

\section{CONCLUSIONES}

A TVWS average spectrum was obtained, which value is around 71.5 MHz. Several uses and application could be developed using this result. A TVWS spectrum per city is showed in the Appendix I.

\section{REFERENCES}

[1] Federal Communications Commision (FCC), "Second report and Order and Memorandum Opinion and Order in ET Docket Nos. 02380 (Additional Spectrum for Unlicensed Devices Below $900 \mathrm{MHz}$ and in the $3 \mathrm{GHz}$ Band) and o4-186 (Unlicensed Operation in the TV Broadcast Bands)," FCC08-260 November 14, 2008.

[2] Office of Communications (Ofcom), "Implementing Geolocation Summary of consulation responses and next steps". Ofcom statement, September 23, 2011.

[3] M.Nekovee, "Cognitive Radio Access to TV White Spaces: spectrum Opportunities, Commercial Applications and Remaining Technology Challenges,". 2010 IEEE Symposium on New Frontiers in Dynamic Spectrum Access Networks, Singapore, April 2010.

[4] S. M. Mishra and A. Sahai, "How much white space has the fcc opened up?" IEEE Communication Letters, 2010.

[5] K. Patil, K. E. Skouby and R. Prasad, "Cognitive access to TVWS in India: TV spectrum occupancy and wireless broadband for rural areas," Wireless Personal Multimedia Communications (WPMC), 2013 16th International Symposium on, Atlantic City, NJ, 2013, pp. $1-5$.

[6] http://www.ift.org.mx/sites/default/files/comunicacion-ymedios/comunicados-ift//comunicado125ift2.pdf

[7] http://www.ift.org.mx/industria/infraestructura

[8] POLÍTICA PARA LA TRANSICIÓN A LA TELEVISIÓN DIGITAL TERRESTRE. Capítulo I. Disposiciones Generales. http://www.dof.gob.mx/nota_detalle.php?codigo $=5359731 \&$ fecha $=1$ 1/09/2014.

[9] Longley-Rice model prediction inaccuracies in the UHF and VHF TV bands in mountainous terrain. Stylianos Kasampalis; Pavlos I. Lazaridis; Zaharias D. Zaharis; Aristotelis Bizopoulos; Lidija Paunovska; Spiridon Zettas; Ian A. Glover; Dimitrios Drogoudis;
John Cosmas. 2015 IEEE International Symposium on Broadband Multimedia Systems and Broadcasting.

[10] http://www.awe.communications.com/Propagation/Rural/ITM/index. htm

[11] B. Scott and M. Calabrese, "Measuring the TV 'White Space' Available for Unlicensed Wireless Broadband," New America Foundation, Tech.Rep., Jan. 2006.

[12] R. Kennedy, K. George, O. Vitalice and W. Okello-Odongo, "TV white spaces in Africa: Trials and role in improving broadband access in Africa," AFRICON, 2015, Addis Ababa, 2015, pp. 1-5.

[13] S. Kawade and M. Nekovee, "Is wireless broadband provision to rural communities in TV whitespaces viable? A UK case study and analysis," Dynamic Spectrum Access Networks (DYSPAN), 2012 IEEE International Symposium on, Bellevue, WA, 2012, pp. 461466.

About Author (s):

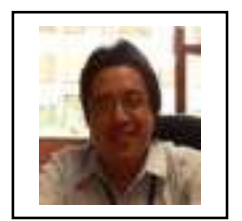

The author currently collaborate in the Centro de Estudios from the Instituto Federal de Telecomunicaciones, México 
Proc. of the Fourth International Conference on Advances in Computing, Electronics and Communication - ACEC 2016.

Copyright (C) Institute of Research Engineers and Doctors. All rights reserved.

ISBN: 978-1-63248-113-9 doi: 10.15224/ 978-1-63248-113-9-60

Appendix I.

TVWS

per

city

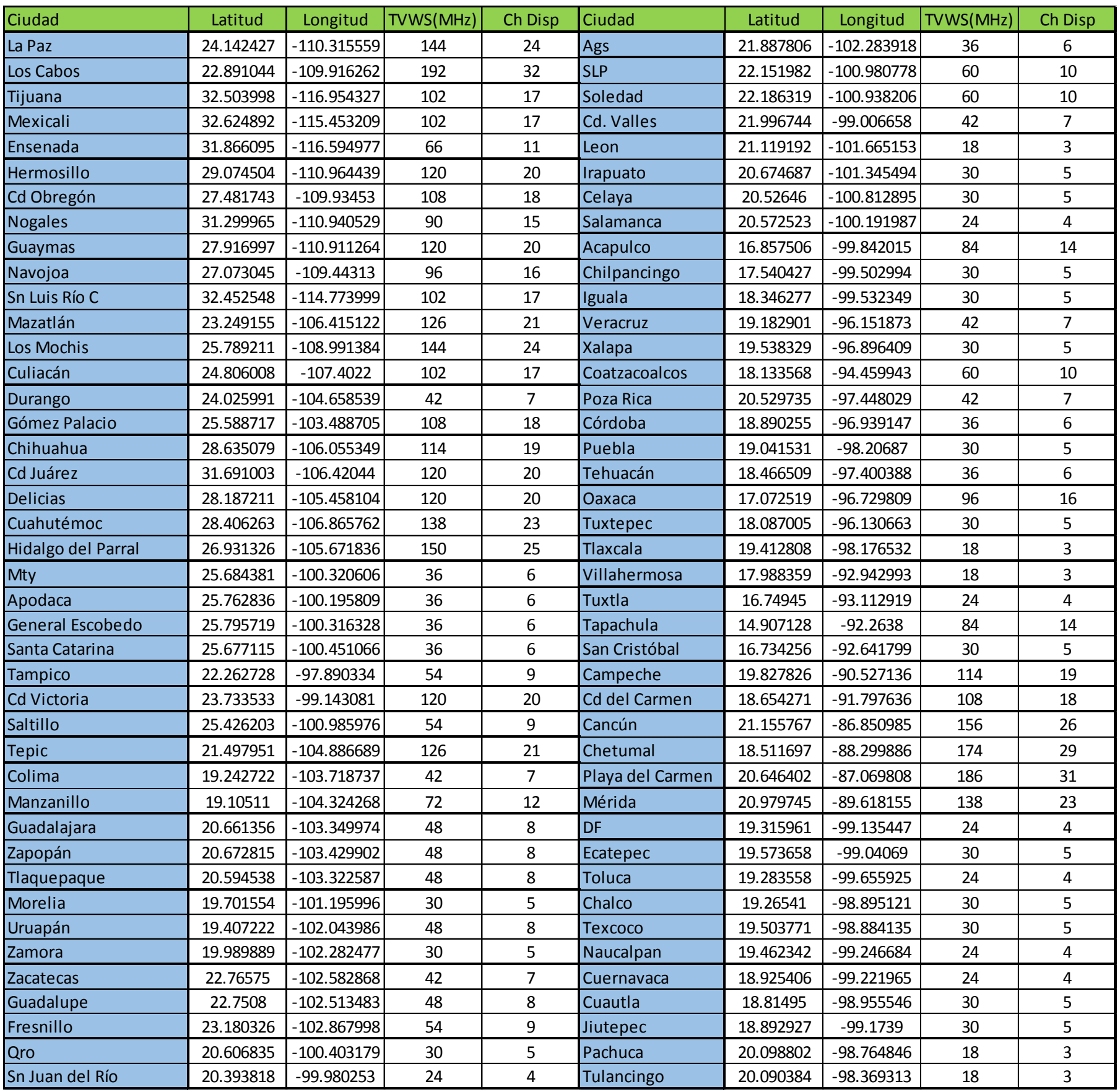

